\title{
La antropología mística de San Juan de la Cruz: una meditación fenomenológica*
}

\section{Lucero González Suárez**}

Recibido: 21 julio de 2015 • Aprobado: 3 de septiembre de 2015

\section{Resumen}

La finalidad de esta meditación es responder a la pregunta ¿qué es el hombre?, a partir del análisis del testimonio místico de San Juan de la Cruz. El texto inicia justificando la idea según la cual, la antropología sanjuanista tiene por principio y fundamento la unión de semejanza amorosa con el Esposo Cristo. A continuación, se muestra que el origen de la existencia se remonta al poder creador del amor divino. Posteriormente, la reflexión se ocupa con el análisis de la condición redimida y encarnada del hombre. La filosofía que aquí desarrollo es antropología por su objeto; fenomenología, por su método; hermenéutica, porque aquello a lo que se dirige la pregunta por el ser del hombre es una construcción textual.

Palabras clave: antropología, mística, San Juan de la Cruz, Dios.

* El presente artículo ha sido posible gracias al apoyo del Programa de Becas Conacyt para Estancias Posdoctorales Nacionales en México.

** Doctora en filosofía con mención honorífica por la Facultad de Filosofía y Letras de la UNAM, México, en el área de filosofía de la religión. Docente de la Licenciatura ejecutiva en educación en Universidad del Valle de México. Correo electrónico: noche_oscura27@yahoo.com.mx 


\title{
The mystique of anthropology Saint John of the Cross. A phenomenological meditation
}

\begin{abstract}
The purpose of this meditation is to answer the question what is the man?, based on the analysis of the mystical testimony of Saint John of the Cross. The text starts justifying the idea according to which, the anthropology of the holy has by principle and based on the union of loving husband Christ resemblance. Then shows that the origin of the existence goes back to the creative power of divine love. Subsequently, the reflection is occupied with analysis of the redeemed and embodied the man's condition. The philosophy of development here is anthropology by its object; phenomenology, its method; hermeneutics, because that what the question is directed by the being of man is a textual construction.
\end{abstract}

Keywords: Anthropology, mystique, Saint John of the Cross, God.

\section{L'anthropologie mystique de Saint Jean de la Croix. Une méditation phénoménologique}

\section{Résumé}

Le but de cette méditation est de répondre à la question: qu'est-ce que l'homme? à partir de l'analyse du témoignage mystique de Saint Jean de la Croix. Le texte commence par justifier l'idée selon laquelle, l'anthropologie de Saint Jean à pour principe et fondement l'union de similitude amoureuse avec l'Époux Christ. Ensuite, on montre que l'origine de l'existence remonte au pouvoir créateur de l'amour divin. Par la suite, la réflexion s'oriente vers l'analyse de la condition récupérée et incarnée de l'homme. La philosophie que je développe ici est anthropologie par son objet; phénoménologie, par sa méthode; herméneutique, parce que cela vers quoi s'oriente la question à propos de l'être de l'homme est une construction textuelle.

Mots-clés: Anthropologie, mystique, Saint Jean de la Croix, Dieu. 
¿Qué es el hombre para que te acuerdes de él, el hijo de Adán para que de él te cuides? Apenas inferior a un dios lo hiciste, coronándolo de gloria y esplendor; señor lo hiciste de las obras de tus manos, todo lo pusiste bajo sus pies (Sal 8, 5-7).

\section{Introducción}

Si es que nuestra vida no ha de agotarse en la dimensión natural que abarca del nacimiento y a la muerte, se impone la necesidad de comprender el enigma que somos. Todo hombre en quien no se haya extinguido por completo el deseo de conocerse a sí mismo, reconoce la necesidad de responder satisfactoriamente a las preguntas por el origen de su existencia; por las determinaciones esenciales de la condición de ser que le es propia; por es el sentido último de su vida.

A pesar de la importancia vital inherente al autoconocimiento, es posible evadir el carácter problemático y enigmático de su existencia. Así se permanece a salvo de la angustia, derivada del descubrimiento originario de que, a diferencia de las cosas que pueblan el mundo y de los seres naturales, cada uno de nosotros no simplemente es sino que, por principio, no sabe quién es; de dónde proviene; cuál es la finalidad de la vida ni qué debe hacer para alcanzar la plenitud a la que aspira. El costo de dicha tranquilidad, que más bien debiera llamarse somnolencia, es carecer de una razón para levantarse día tras día. Quien ignora su ser, no puede siquiera preguntarse seriamente si hay alguna misión que deba realizar, por la cual vivir y morir; solo vive y se sobrevive, extraviado en los afanes cotidianos. Tal hombre está condenado al sinsentido, ya que, sin importar cuán exitoso o eficiente sea en la realización de cierta profesión u oficio, está inmerso en la inmediatez. Y por más objetivos y metas que se haya planteado, a corto o largo plazo, su vida no tiene un por qué ni un para qué.

La pregunta por el ser del hombre, que especifica el objeto material de la antropología filosófica, es la más importante de todas en términos existenciales. Su pretensión no es simplemente generar un conocimiento libre y desinteresado acerca de quiénes somos; sino aportar elementos que nos ayuden a decidir si nuestra vida tiene o no algún sentido y en qué consiste. La reflexión sobre el ser del hombre no se limita a ofrecer una respuesta racional que nos permita comprender nuestra singularidad ontológica. Al responder a la pregunta por el sentido de la existencia, la reflexión antropológica permite juzgar el valor de las acciones a través de las cuales el existente se aproxima o se aleja de la realización de dicho sentido. La antropología filosófica tiene un carácter normativo, en 
la medida en que no se limita a describir cómo es el hombre, en determinadas circunstancia histórico-culturales; sino que, al ofrecer una respuesta rigurosa y sistemática a la pregunta ¿qué es el hombre?, ofrece indicaciones éticas sobre lo que el hombre ha de hacer, para alcanzar la realización de su esencia.

Toda reflexión filosófica que no sea estéril ha de partir de la experiencia y ha de retornar a ella para explicarla y dotarla de sentido. La pregunta por el ser del hombre, solo puede ser respondida para atender al ente al que ella apunta. Pero es al mirar al hombre como se puede descubrir quién es. Ahora bien, dado que la existencia adopta una gran diversidad de modalidades, de ello se sigue la necesidad de decidir a qué tipo de hombres se ha de dirigir la mirada, a fin de indagar sobre nuestra condición de ser. La postura de la fenomenología es que a fin de dilucidar la estructura y las determinaciones esenciales de aquello que aparece, es necesario atender a su manifestación más acabada y plena. Lo que implica que el filósofo debe distinguir por principio entre las manifestaciones más originales y las expresiones degradadas del fenómeno a investigar. Para responder a la pregunta por el ser del hombre, no se ha de atender al hombre promedio, que jamás se ha preguntado quién es y que, por eso mismo, vive inmerso en el sinsentido; sino a aquella manifestación de la humanidad en la que se encuentren realizadas todas las posibilidades de la existencia que implican excelencia. Posibilidades de entre las cuales destaca la figura del místico, toda vez que en él hay una clara consciencia del origen, las determinaciones esenciales y la finalidad última de la existencia.

El propósito de estas páginas es responder a la pregunta de la antropología filosófica, y toma como punto de partida para el análisis un fenómeno hermenéutico: la obra poética y doctrinal de San Juan de la Cruz (SJC). La filosofía que aquí desarrollo es antropología por su objeto; fenomenología, por su método; hermenéutica, porque aquello a lo que se dirige la pregunta es un testimonio escrito sobre la plenitud de la vida que se abre a la experiencia de Dios.

A fin de cumplir con dicho objetivo, la meditación filosófica comienza por ubicar la pregunta por el ser del hombre en el contexto de la experiencia mística, a fin de exhibir el alcance de la antropología sanjuanista. A continuación, se muestra que el origen de la existencia se remonta al poder creador del amor divino. Posteriormente, la reflexión se orienta al análisis de dos determinaciones esenciales del ser del hombre: su condición redimida y encarnada.

Tanto en la tradición francesa como en la española se ha realizado gran cantidad estudios filosóficos y teológicos, destinados a exponer la psicología y la antropología de SJC. Sin embargo, hasta donde yo sé, nadie ha intentado el análisis 
fenomenológico de la obra del santo con el propósito de enfatizar que el misticismo no es un modo de vida extraordinario, propio de algunos elegidos; sino la plenitud a la que está llamado todo hombre. La misma que consiste en hacerse semejante al Esposo Cristo, en el ejercicio del amor perfecto que se manifestó en la cruz.

\section{La Experiencia Mística: Origen Y Fundamento De La Antropología Sanjuanista}

Para SJC, la pregunta por la esencia, el origen y la finalidad de la existencia humana están íntimamente relacionadas. Al referirse a ellas, el santo retoma el discurso de la tradición. Su aportación a la antropología no consiste en haber propuesto nuevas categorías de análisis para esclarecer el ser del hombre, sino en el hecho de que su comprensión no surge de un conocimiento discursivo, sino de la experiencia directa de Dios.

El lenguaje de SJC no es el de un teólogo ni el de un filósofo, sino el de un espiritual, con formación filosófica y teológica, que ha llegado a la cima de perfección; que ha sido favorecido con la unión de semejanza amorosa con el Esposo Cristo. Y que a lo largo del proceso místico, en la iluminación oscura de la fe, ha alcanzado una comprensión privilegiada tanto del Misterio de Dios como del hombre; del Amado y de la amada.

El discurso de SJC sobre el hombre no es fruto de la reflexión; es el eco de un encuentro amoroso con Dios. Enfrentamiento del que resulta no solo un conocimiento sobrenatural sobre el ser de Dios y sobre la finitud e imperfección de la existencia; sino también el reconocimiento de la apertura esencial del hombre a lo divino. Cuando el poeta místico habla del hombre, lo hace desde su experiencia contemplativa. Su noción de "hombre-alma" no procede del conocimiento natural; surge de la virtud teologal de la fe, que Dios le infunde por gracia.

En tanto que proceso, la mística se define por una transformación de la concepción que el espiritual tiene de sí mismo, del mundo y de lo divino. Como señala Isabel Cabrera:

[...] lo que parece ocurrir en última instancia a lo largo del proceso místico es algo particularmente interesante: a lo largo de la búsqueda puede detectarse una paulatina transformación del concepto de la deidad o, en términos más generales, de lo sagrado, a la par que una 
trasformación en la concepción del propio sujeto de la mística. (Cabrera, 2006: p. 11).

Quien accede a la experiencia de Dios, rebasa la comprensión ingenua de la realidad -de lo humano, de lo divino, del mundo, de los otros y de las cosas- para acceder a un saber que no se limita a lo que enseña la tradición, a lo que "se dice"; sino que tiene su origen en la luz sobrenatural de la fe. Místico es quien, como Job, después de ser interpelado por Dios, cae en la cuenta de la enorme distancia que hay entre simplemente repetir lo que la tradición dice sobre el ser de Dios, del hombre y del mundo, y acceder a su comprensión originaria, a través de la iluminación de la sabiduría divina. Es místico quien, en presencia de Dios, está en condiciones de decir "Sólo de oídas te conocía, pero ahora te han visto mis ojos" (Job 42, 5).

Aún cuando al hablar del ser del hombre SJC retoma las categorías filosófico-teológicas de su tradición, en el contexto de sus obras, dichos términos cobran un significado nuevo: su sentido se dilata para acoger la iluminación proveniente de la sabiduría divina, de la que el hombre participa en la contemplación.

\section{El Poder Creador del Amor Divino: Origen de la Existencia.}

El libro del Génesis nos relata en estos términos la creación del hombre: "Creó, pues, Dios al ser humano a imagen suya, a imagen de Dios lo creó, macho y hembra los creó" (Gn 1, 27). El pasaje resulta familiar para todos los cristianos. Pero al escucharlo, ¿realmente comprendemos que el haber sido creados a imagen de Dios supone que la finalidad de nuestra vida es convertirnos en reflejo de su perfección?

Ser imagen de Dios significa que cada uno de nosotros es, por esencia, una manifestación finita de Dios. Cada hombre es semejante a un espejo o, para usar una hermosa expresión de Santa Teresa de Jesús, a "un diamante u muy claro cristal" (De Jesús, 1972: p. 36), donde se refleja de forma única la presencia de Dios. Cuando el espejo está libre de impurezas, se parece a un río cristalino o a un manantial en cuyas aguas se refleja la belleza de lo creado; pero cuando se haya cubierto de imperfecciones, es semejante al agua mezclada con fango, que ha perdido su poder para manifestar presencia alguna.

El propósito de la actitud ascética es hacer del alma un espejo limpio donde pueda reflejarse en todo su esplendor la presencia de Dios. La finalidad de 
las prácticas y ejercicios que buscan eliminar las inclinaciones equivocadas de la voluntad -que constituyen la raíz de los vicios y pecados- es la purificación del hombre. La pureza es condición de posibilidad de que podamos dar testimonio de la presencia de Dios en nuestro ser, según nuestra condición espiritual y carácter, puesto que la manera en la que somos habitados por Dios "no opera en el vacío, sino que respeta y tiene en cuenta el propio modo de ser humano." (Graef, 1970: p. 70)

Cuando el espejo que somos está manchado por nuestros pecados y apetitos voluntarios, por más que Dios siga habitando en el castillo interior de nuestra alma, somos incapaces de percibir e irradiar su presencia. Pero cuando el proceso de purificación y limpieza progresa, los vicios e imperfecciones que han usurpado el castillo comienzan a retirarse. Entonces, comienza a relucir la presencia interior de Dios en cada uno.

$\mathrm{Al}$ referirse a la condición creatural del hombre, SJC explica que tanto la existencia como la esencia del hombre, son efectos del poder creador de Dios, que tiene por origen y fin el amor-ágape. Respecto de Dios, el amor-ágape es la esencia de su ser, por amor crea al hombre. Con relación al hombre, el amor-ágape es el principio y la razón última de su existencia. Dios ha creado al hombre por amor y para amar, y toma como modelo a "la Sabiduría suya por quien las crió, que es el Verbo, su unigénito Hijo (cf. Col 1, 16)" (De la Cruz, 1994b: 5, 1).

En términos ontológicos, Dios es trascendente respecto del hombre y del mundo, en el sentido de que estos últimos tienen la razón de su existencia y conservación en Dios; pero Dios no depende en forma alguna de sus creaciones. Sin embargo, bajo otro aspecto, Dios es inmanente al hombre, toda vez que, conforme a la revelación, la creación del mundo no tiene la forma de un acto productor que el Hacedor o el Demiurgo, haya realizado al fijar la mirada en lo eterno e idéntico para tomarlo como modelo. En el Timeo,

Platón habla de «producir», de un «acto de hacer», de una «hechura». El verbo utilizado es poieo; su significado: fabricar, ejecutar, confeccionar; crear, producir, en el sentido de engendrar, dar a luz, producir el suelo, hacer nacer, causar; actuar, ser eficaz (Pérez, 2002: p. 130).

Por otro lado, en el libro del Génesis, la creación es descrita como un acto que pone en existencia lo nuevo, que crea al mundo y al hombre, al palacio y a la esposa, los llama a ser desde la nada, a fin de que, a su modo y según su capacidad, puedan participar del amor que define la esencia divina. Al hablar del los orígenes del hombre y del mundo, el Nuevo Testamento no califica la acción divina 
como "hacer", ni "producir"', sino como "crear". "Esta nueva palabra significa en griego clásico construir casas o ciudades; fundar una colonia; instituir"(Pérez, 2002: p. 131).

El modelo para la creación del mundo; para su creación desde la nada, no es un arquetipo presente en el entendimiento divino, ni una forma preexistente, que la voluntad de Dios elige por su perfección relativa y que su potencia crea. El modelo conforme al cual ha tenido lugar la creación es el Hijo, que se identifica con la Sabiduría de Dios. Al mundo y al hombre,

sola la mano de el Amado Dios [es decir, del Verbo] pudo hacerlas y criarlas [...] porque, aunque otras muchas cosas hace Dios por mano ajena [...] esta que es criar nunca la hizo ni la hace por otra que por la suya propia (De la Cruz, 1994a: 5, 3).

La creación es tarea única del Dios Trinitario, puesto que “En el principio existía la Palabra, la Palabra estaba junto a Dios y la Palabra era Dios. Ella estaba en el principio junto a Dios. Todo se hizo por ella y sin ella no se hizo nada" (Jn 1, 1-3). La creación es obra conjunta del Padre y el Hijo, en la unidad del Espíritu Santo. Es por ello que en lo creado se expresa parcialmente la perfección de Dios, quien

crió todas las cosas con gran facilidad y brevedad y en ellas dejó algún rastro de quien El era, no sólo dándoles el ser de nada, mas aun dotándolas de innumerables gracias y virtudes, hermoseándolas con admirable orden y dependencia indeficiente que tienen unas de otras; y esto todo haciéndolo por la Sabiduría suya, por quien las crió, que es el Verbo (De la Cruz, 1994a: 5, 1).

Al hablar de la creación, el poeta místico asume tanto la perspectiva paulina como la joanea afirma que si al crear al mundo y al hombre, toma como modelo al Hijo, Dios ya había dotado de dones a las criaturas, el perfeccionamiento y la exaltación de lo creado tiene lugar gracias a la encarnación. Por obra de la encarnación, todo aquello que es asumido, es también exaltado. Si el Verbo se hizo carne fue para que el hombre estuviera en condiciones de hacerse Dios por participación. Pero la encarnación del Verbo no solo dotó de dignidad al hombre sino que elevó a un estado de mayor perfección al mundo.

Es, pues, de saber que con sola esta figura de su Hijo miró Dios todas las cosas, que fue darles el ser natural, comunicándoles muchas gracias y dones naturales, haciéndolas acabadas y perfectas [...]. Y no solamente les comunicó el ser y gracias naturales mirándolas, como hacemos 
dicho, mas también con sola esta figura de su Hijo las dejó vestidas de hermosura, comunicándoles el ser sobrenatural; lo cual fue cuando se hizo hombre, ensalzándole en hermosura de Dios y, por consiguiente a todas las criaturas con él, por haberse unido con la naturaleza de todas ellas en el hombre." (De la Cruz, 1994a: 5, 4).

El texto revelado que resuena en la afirmación recién citada de SJC es: “y cuando sea elevado de la tierra, atraeré a todos hacia mí" (Jn 12, 32). Aquello a lo que el santo alude es el hecho de que, en la resurrección, cuando el Verbo Encarnado -que es también Cristo Crucificado- asume la forma de Señor exaltado, atrae hacia sí la creación entera. Por lo cual dice que "en este levantamiento de la encarnación de su Hijo y de la gloria de su resurrección según la carne, no solamente hermoseó el Padre las criaturas en parte, mas podemos decir que las dejó vestidas de hermosura y dignidad." (De la Cruz, 1994a: 5, 4)

En sí mismas, las criaturas -sobre todo el hombre- son rastros de la perfección del Amado, a través de los cuales se hace manifiesta la existencia y perfección de Dios. No obstante, hasta que no se haya purificado el sentido, el goce en la consideración y posesión de las criaturas constituye un riesgo de alienación. Para la voluntad desordenada, que se goza en la posesión egoísta de los bienes finitos, la presencia de las criaturas puede resultar peligrosa en la medida en que, sin considerar que comparadas con el ser de Dios, las criaturas son poco menos que nada, el hombre puede olvidarse del fin sobrenatural de la existencia. Esto es, puede olvidarse del Creador, por amor a lo creado.

Entre la manera en que SJC habla de las criaturas en la Subida del Monte Carmelo y la manera en que lo hace en el Cántico Espiritual B hay una gran diferencia. Lo cual se debe no a que el objeto sea distinto, sino a la perspectiva desde la cual es contemplado: como fin en sí mismo y como huella de la presencia divina, respectivamente. Cuando en la Subida del Monte Carmelo se refiere a la necesidad de la purificación activa del sentido, SJC enfatiza la distancia infinita que hay entre las criaturas y el Creador. Y pregunta en todo irónico: “¿qué tiene que ver criatura con Criador, sensual con espiritual, visible con invisible, temporal con eterno?" (De la Cruz, 1994b: 1, 6, 1). Por sí mismas, sin relación con el principio del que proceden, el ser de las criaturas carece de sustento alguno. Es por ello que, tras compararlas con el ser de Dios, haya que concluir que las criaturas son "nada". No obstante, hay que recordar que el origen de la distancia es el pecado, que impide al hombre la contemplación de las criaturas en Dios. Por su parte, el Cántico Espiritual B celebra el reencuentro con la creación del alma que ya ha pasado por las purificaciones activas y pasivas del sentido y del espíritu. Para la esposa, las criaturas son mediaciones 
de la presencia divina. Lo que ocurre es que tan pronto aparta el gozo de los bienes finitos, el alma "Adquiere más gozo y recreación en las criaturas con el desapropio de ellas"(De la Cruz, 1994b: 3, 20, 2).

\section{El Hombre: Ser Redimido.}

El amor divino es la razón de ser de la creación del hombre y del mundo. Para que llegara a la perfección del amor-ágape y, de ese modo, se hiciera co-partícipe de su vida y operaciones, "crió y redimió"(De la Cruz, 1994c: 12) Dios al hombre.

Creación y redención han sido las mayores obras que el Padre ha llevado a cabo, por mediación del Amado Esposo Cristo, con quien el místico anhela unirse. No obstante, al comparar ambas, SJC sostiene que "la mayor obra que en toda su vida hizo Cristo fue reconciliar al género humano por gracia con Dios")(De la Cruz, 1994b: 2, 7, 11). La misión que dio origen a la Encarnación del Verbo; que se manifestó en la vida y llegó a su consumación en la muerte y resurrección del Hijo, es la Redención. La vida, predicación, muerte y resurrección de Jesús, comprendidas unitariamente a la luz de su misión redentora, constituyen el acontecimiento central de la revelación neotestamentaria.

Cristo es el Dios que, en palabras del Credo Niceno-Constantinopolitano, se encarnó, padeció, fue crucificado y resucitó «por nosotros y por nuestra salvación». La encarnación y muerte de Cristo tuvieron por fin liberar al hombre del pecado. “Cristo murió por nuestros pecados, conforme a las Escrituras" (1 Co 15, 3). Cristo asumió voluntariamente los pecados de la existencia para su redención cuando, inmerso en la más honda experiencia de abandono divino, "fue entregado por nuestras transgresiones, y resucitado para nuestra justificación" (Rom 4, 25).

Para comprender el misterio de la redención, la teología ha propuesto dos modelos complementarios: el del movimiento descendente, que va de Dios al hombre; el movimiento ascendente, que va del hombre regenerado a Dios, y que alcanza su máxima expresión en la transformación de semejanza amorosa con la que llega a su perfección el proceso místico. El primer modelo, designa el movimiento por el cual "el Verbo encarnado viene a liberarnos de las cadenas del pecado y de la muerte y a comunicarnos con la adopción filial la vida misma de Dios" (Sesboüé, 1997: p. 116). El movimiento ascendente se refiere "a lo que corresponde al hombre para reparar su pecado, convertirse a Dios y encontrar la reconciliación con él." (Sesboüé, 1997: p. 116). 
Conforme a su sentido teológico, el término redención designa la acción salvífica de Dios con respecto al pueblo de Israel. Experiencia que, al ser retomada por el cristianismo, se utilizó para nombrar el sentido de la cruz de Cristo. Ahora bien,

los escritores del Nuevo Testamento no se extienden nunca sobre la idea de rescate en sí misma para explicar la cruz, sino más bien sobre la liberación de la esclavitud que resulta de ella, con su contrapartida en la reconciliación con Dios de los esclavos liberados, que son por este hecho son adoptados por Él como hijos, en el Hijo que los ha rescatado. La esclavitud de la que somos rescatados por Cristo es la del pecado (cf. Rom 6, 18 y 8, 2), de la muerte (Rom 8, 21; 2 Cor 1, 10). (Bouyer, 2002: p. 317)

Para comprender el sentido de la redención es preciso ponerla en relación con la reconciliación entre Dios y el hombre. Lejos de pensar el sacrificio de Jesús bajo el esquema de la propiciación, es preciso recordar que la muerte de Jesús en la cruz tiene por causa el pecado de los hombre, en dos sentidos.

En un primer sentido, fue la condición pecadora de todos los hombres lo que motivó la encarnación, y la redención de la cruz. La cruz del Hijo, aceptada voluntariamente por amor al hombre y al Padre, es el máximo símbolo de la salvación. La cruz de Cristo es el acontecimiento radical por el que Dios se hace hombre para regenerar la naturaleza humana, estragada por el pecado, y otorgarle al hombre la capacidad de participar de la vida eterna: de amar como Dios nos amó a todos en Cristo.

La finalidad última de la redención es la salvación del hombre. "La salvación, es la salud, es decir, la plenitud de la vida; es también la libertad" (Sesboüé, 1997: p. 120). A fin de interpretar en su justa dimensión la relación entre redención y salud, es necesario traer a la memoria el hecho de que, a diferencia del pensamiento moderno, la cosmovisión judía establece una clara vinculación entre enfermedad y pecado, según la cual, la enfermedad es el signo a través del cual se manifiesta el pecado.

La actitud habitual del pueblo de Israel ante los enfermos era de desprecio. Bajo la influencia de la teología del mérito, los judíos identifican al pecado como la causa espiritual de la enfermedad. Así, por ejemplo, en el libro de Números, se dice que María, la hermana de Moisés, se negó a respetar la autoridad del primero y a criticarlo, con el apoyo de Aarón. A causa de lo cual, "El señor se enojó con ellos y se fue. Y cuando la nube desapareció del Tabernáculo, María apareció cubierta con una lepra blanca como la nieve." (Num 12,9) 
Para los judíos, la enfermedad era la señal más clara de la corrupción espiritual del hombre. Con ocasión de la enfermedad, el hombre reconoce su impotencia, su limitación y su finitud; comprende que su existencia no se sostiene en y por sí misma sino que depende de otra instancia: el poder divino. Es por ello que la enfermedad era considerada como una oportunidad de examinar la propia consciencia, a fin de reconocer la transgresión de la Ley y rogar por el perdón de los pecados, bajo la confianza de que Dios tiene entrañas de misericordia. De modo que, cuando castiga justamente a sus hijos, lo hace para llamarlos a la conversión y regenerarlos.

En el discurso y las acciones de Jesús, la salud se convierte en metáfora y signo de la salvación. Jesús es el médico del hombre, porque a través suyo tiene lugar la redención, que constituye el fruto del árbol de la cruz. En el contexto judío, la actitud de Jesús es desconcertante: se aproxima a los enfermos, los toca, los sana y les permite reintegrarse a una sociedad de la que habían sido expulsados por su impureza. En las acciones de Jesús se manifiesta la presencia salvadora del Espíritu Santo: tal es la fuente de donde surge el poder de sus palabras: “Tu fe te ha salvado", y "tus pecados te son perdonados".

Asimismo, la redención tiene el sentido de la liberación del mayor de los males: aquel que no padecemos sino que, sin necesariamente quererlo, obramos: el pecado que degrada nuestra condición, atenta contra el otro y ofende a Dios. La redención satisface el deseo humano de plenitud. Lo que la redención nombra es el hecho de que la libertad para el bien y la salud solo pueden provenir de Dios porque son dones. "Esta salvación es simbolizada, inaugurada y dada a la vez por la resurrección de Cristo." (Sesboüé, 1997: p.121)

Al referirse al fruto del árbol de la cruz, SJC señala que si "por medio del árbol vedado del paraíso fue perdida y estragada en la naturaleza humana por Adán" (De la Cruz, 1994a: 23, 2); en el árbol de la cruz, fue salvada por la entrega amorosa del Hijo. Adán representa la pérdida del vínculo inmediato entre el hombre y Dios; la ruptura entre la voluntad divina y la del hombre, que constituye la esencia del pecado. Cristo es el modelo del hombre nuevo, que se opone al viejo en su capacidad para responder a la iniciativa del amor divino, aún a costa de la propia vida.

en el árbol de la cruz [la amada] fue redimida y reparada, dándole allí [el Esposo] la mano de su favor y misericordia por medio de su muerte y pasión, alzando las treguas que del pecado original había entre el hombre y Dios. Y así dice: Debajo del manzano. Esto es, debajo del favor del árbol de la Cruz, que aquí es entendido por el manzano, 
donde el Hijo de Dios redimió y, por consiguiente, desposó consigo la naturaleza humana, y consiguientemente a cada alma, dándola él gracia y prendas para ello en la Cruz (De la Cruz, 1994a: 23, 2-4).

Para SJC, la cruz de Cristo es "desposorio que se hizo de una vez, Dios [da] al alma la primera gracia, lo cual se hace en el bautismo con cada alma"(De la Cruz, 1994a: 23, 6). Para redimir al hombre de su condición pecadora, Cristo tenía que hacerse solidario con él al cargar con sus pecados. “Jesús había cargado con la culpa de toda la humanidad; entró en ella en el Jordán. Inicia su vida pública tomando el puesto de los pecadores" (Ratzinger, 2007: p. 40). Aquello que funda la condición mediadora de Jesús es la "doble solidaridad con Dios y con los hombres." (Sesboüé, 1997: p.122)

El bautismo del Hijo, comprendido como anticipación de la pascua, señala el momento en que Éste asume el pecado de todos los hombres. La importancia del bautismo de Cristo radica en que solo lo que es asumido puede ser salvado; gracias a que Cristo se hizo solidario de los pecados del hombre -lo que no quiere decir que incurriera en pecado alguno- pudo redimirlo de su enfermedad y muerte espirituales y regenerarlo, para que recobrara la amistad de Dios.

El bautismo-desposorio de la cruz de Cristo es condición de posibilidad de la unión mística. Cristo es el mediador de una nueva alianza, que no viene a cancelar sino a perfeccionar la antigua. El sentido de la nueva relación que él hace posible entre Dios y el hombre tiene el signo de la participación en la vida ad intra de la Trinidad. La correspondencia de la amada a la llamada del amor divino, constituye la realización plena de la comunión con Dios, que el misterio de la redención ha hecho posible. Comunión que consuma en el matrimonio espiritual, que consiste en la unión amorosa con el Amado "por vía de perfección." (De la Cruz, 1994a: 23, 6).

Para entrar en comunión con el Amado Esposo Cristo, la amada tiene que compartir su muerte, para luego compartir la resurrección. Tal es el sentido profundo de las purgaciones activas y pasivas del sentido y del espíritu, que definen a la noche oscura.

El amor radical de Dios en Cristo mostró la dureza de la cruz, pues:

cierto está que al punto de la muerte quedó también anihilado en el alma sin consuelo y alivio alguno, dejándole el Padre así en íntima sequedad según la parte inferior, por lo cual fe necesitado a clamar diciendo: ¡Dios mío, Dios mío, ¿por qué me has desamparado? (Mt 27, 46); lo cual fue el mayor desamparo sensitivamente que había tenido en su vida; y así, en 
él hizo la mayor obra que en [toda] su vida con milagros y obras había hecho un en la tierra ni en el cielo, que fe reconciliar y unir al género humano por gracia con Dios. (De la Cruz, 1994b: 2, 7, 11)

Del mismo modo, el amor perfecto del hombre se prueba en las estrecheces y los aprietos de la noche oscura. Por lo cual dice SJC que, para emprender el camino de perfección, lo primero es traer "un ordinario apetito de imitar a Cristo en todas sus cosas, conformándose con su vida, la cual debe considerar para saberla imitar y haberse en todas las cosas como e hubiera él (Io 13, 15)." (De la Cruz, 1994b: 1, 13, 3)

Es en el padecimiento por la ausencia afectiva del Amado, donde surge el amor desnudo, que no busca la proximidad del Esposo al tener como motivación el goce egoísta ni el interés por la propia salvación; sino que surge de modo gratuito. A lo cual se refiere el poeta místico cuando dice que el amor-ágape es hábito infuso del que la esposa se hace merecedora por "las obras hechas en sequedad y dificultad de espíritu" (De la Cruz: 1994a, 30, 5). Las obras del amor que le valieron a la amada la unión de semejanza fueron las que realizó en sequedad de espíritu, durante su trayecto por la fase más oscura de la noche, donde su más grande pena es la ausencia efectiva del Amado. No obstante, en la cruz, Jesús estaba solo; mientras que en el sufrimiento por la lejanía del Amado, el místico tiene en el recuerdo de la cruz del Amado el consuelo de que nunca lo está.

Respecto de la redención, la obra del Hijo es cumplir la misión del Padre; la del Padre, es enviar a su Hijo unigénito a los hombres y resucitarlo después de la crucifixión. Para no incurrir en el grave error de responsabilizar al Padre de la muerte del Hijo, es necesario recordar que fueron los hombres quienes juzgaron, despreciaron y crucificaron al Hijo; no al Padre. El rechazo de la predicación y la muerte de cruz del Hijo, tienen por causa los pecados de los hombres; no la voluntad divina.

Cristo "ha cumplido hasta el extremo, en espíritu de obediencia y de amor, la misión de salvación que ha recibido del Padre, y esto incluso a costa de su vida" (Sesboüé, 1997: p.114). El testimonio del amor perfecto forma parte del proyecto de Dios del que participan el Padre y el Hijo en la unidad del Espíritu Santo. Cristo es el Verbo encarnado, donde confluyen eternidad y temporalidad; finitud e infinitud, humanidad y divinidad. Cristo es verdadero Dios y verdadero hombre; es el Emmanuel, el Dios con nosotros y por nosotros. La misión que ha venido a cumplir es "que los hombres tengan vida y la tengan en abundancia" (Jn 10,10), a través de la inhabitación del Espíritu Santo, que procede del Padre y del Hijo: que el Padre hace descender sobre el Hijo; que el Hijo encomienda al Padre 
en el momento de su muerte y recobra en la resurrección. Mismo que envía a los hombres, a fin de habilitar su naturaleza para que, habitados del espíritu de Dios, llenos de su presencia, puedan corresponder a su llamado amoroso.

El Espíritu Santo es "la misma fuerza de amor con que es amada de Dios" (De la Cruz, 1994a: 38, 3). El Espíritu Santo es el responsable de la "junta espiritual" (De la Cruz, 1994a: 20, 2) entre Dios y el hombre. Pues cuando el alma se ejercita en el amor perfecto que procede de Dios, en el amor-ágape, lo hace en virtud de la inhabitación del Espíritu Santo.

Conforme a su humanidad, Cristo realiza la plena correspondencia al amor divino. En su vida, su pasión, su muerte y su resurrección, confluyen el movimiento descendente, que señala el camino de Dios al hombre; y el ascendente, que se expresa en el itinerario espiritual del hombre que busca la unión con Dios, cuya máxima realización es el misticismo. La vida terrena de Cristo revela que "El don de Dios al hombre presupone, en efecto, que sea acogido y recibido. Ahora bien, la acogida del hombre del don de Dios no puede consistir más que en el don del hombre a Dios"' (Sesboüé, 1997: p.124). Dios se encarna para habitar entre los hombres y, como el novio, seduce con su presencia a la novia para enamorarla, desposarla y rescatarla de su bajo estado de esclavitud, derivada de los apetitos y gustos mundanos que la apartan del camino de perfección. El místico es la novia que, "con ansias en amores inflamadas", se esfuerza por salir del mundo y de la casa de su sensualidad, para salir corriendo en pos de las huellas del Amado.

\section{El Hombre: Ser Encarnado.}

En el Cántico Espiritual B, al hablar del desposorio espiritual -que es el momento del proceso místico en el que la amada, en la iluminación de la fe, cobra consciencia de

[...] sus excelencias y grandes riquezas y que no las posee como querría, a causa de la morada que hace en carne echa de ver que está en el cuerpo como un gran señor en la cárcel, sujeto a mil miserias, y que le tienen confiscados sus reinos y impedido todo su señorío. (De la Cruz, 1994a: 18, 1)

¿Cómo entender dicha afirmación y dejar a un lado el lenguaje de la filosofía escolástica? En primer lugar, es preciso aclarar que cuando el santo utiliza el concepto "alma", lo hace en dos sentidos: a) para referirse al ser humano como ser unitario; b) para aludir al principio de la existencia, esto es, al núcleo 
de donde proceden la totalidad de las acciones que definen nuestro modo de ser, tales como conocer, desear, amar, entender, recordar e imaginar.

En la frase recién referida, "alma" es un concepto que dice relación a la dimensión del hombre, en virtud de la cual éste es capaz de la experiencia de Dios. En dicho contexto, "alma" y "cuerpo" no designan partes o elementos constitutivos del existente; nombran la totalidad de la existencia en su unidad concreta, pero referida a la posibilidad de entrar en contacto con las realidades finitas y con Dios, respectivamente.

En la existencia concreta, lo que se manifiesta no es la unidad de dos substancias, una de las cuales estaría subordinada a la otra; sino una presencia efectiva -la del existente- que a través de sus discursos, acciones, silencios y renuncias, da cuenta de una determinada orientación vital, que puede estar dirigida al plano trascendente o bien permanecer anclada en la inmediatez y finitud del mundo.

Cuando SJC habla del hombre como un alma atrapada en una cárcel, no hay que entender que el sentido de tales palabras alude a la coexistencia de dos substancias separadas. El hecho de que se sirva de tales conceptos filosóficos para expresar su idea de hombre, no es un elemento suficiente para afirmar que su interés sea avalar la metafísica platónica. Antes que ser heredero de Platón y de los neoplatónicos -como pretenden algunos intérpretes, más interesados en rastrear posibles y remotas influencias filosóficas en los escritos del santo que en comprender la manera en que SJC se apropia de su tradición-, el poeta místico es seguidor de San Pablo: es en los escritos paulinos donde habría que buscar el sentido existencial de la oposición alma-cuerpo.

Para SJC, aunque "cuerpo" y "alma" sean substancias vinculadas entre sí por un nudo inefable en el plano metafísico; lo que el espiritual descubre durante el proceso místico es que, de suyo, "cuerpo" y "alma" son nociones que nombran inclinaciones existenciales diversas. Lo que implica reconocer que la unidad de la existencia es una armonía de tensiones opuestas y no una realidad simple. El ser del hombre es conflictividad, que puede asumir la forma de pecado; pero que también puede ser armonizada mediante las purificaciones activas y pasivas, del sentido y del espíritu.

Como señala Gabriel Marcel, la encarnación es "la situación de un ser que se presenta como ligado a un cuerpo" (Kauffman, 2013: p. 75). En tanto que ser encarnado, el hombre el existente no "tiene un cuerpo"; es un cuerpo. Su ser corpóreo es la condición de posibilidad de su ser en el mundo. Solo en virtud de su encarnación, el hombre puede convertirse en una presencia que hace frente, dentro del mundo. La encarnación es el fundamento tanto de la manifestación 
como de la apertura del hombre a los otros, al mundo y a Dios. Solo el ser encarnado puede habitar el mundo: habérselas con los otros y con entes que le salen al paso cotidiana y regularmente, e incluso rastrear la huella del paso del Amado por la creación.

Como heredero de la tradición aristotélico-tomista, SJC sostiene que la sensibilidad, cuyo fundamento es el ser encarnado del hombre, es el principio del conocimiento humano. En tanto que somos cuerpo, no solo estamos en condiciones de afectar y ser afectados por la presencia de las realidades sensibles. A partir del contacto con lo que nos rodea, no solo nos percatamos de la diferencia ontológica entre nuestro ser y el de las cosas. Cuando su presencia es capaz de despertar en nosotros el asombro, nos dirigimos hacia ellas con la intención declarada de sobrepasar el conocimiento de término medio del que ya siempre estamos en posesión, para preguntarnos por la razón de su existencia; por su origen; por su finalidad última y por su sentido. Y sin embargo, tan pronto intentamos conocer la esencia de las cosas, nos topamos con nuestra limitación, con la verdad innegable de que lo único que sabemos a la perfección, es que ni ahora ni nunca podremos conocerlo todo, ni del todo.

Tal es la experiencia que conduce a la conclusión de que, quizás, si nuestro ser no tuviera la condición de ser encarnado, libres de tal limitación, podríamos incluso conocer lo absoluto. Lo que conduce a la especulación de que, si fuéramos espíritus descarnados, podríamos acceder al conocimiento que escapa al alcance de nuestro entendimiento. En todo caso, lo anterior pone de manifiesto que en cada uno de nosotros hay una aspiración a lo infinito, que encuentra su límite en nuestro ser encarnado.

Asimismo, la presencia de los otros y de las cosas que pueblan el mundo no es algo que pase desapercibido. La percepción de las cosas y de los otros, su conocimiento incipiente, lleva aparejada una respuesta afectiva. El encuentro con los entes intramundanos no nos deja impasibles; provoca una movimiento que oscila entre dos polos: el deseo de su posesión y la repulsión ante su presencia. Percibir es, al mismo tiempo, verse afectado por el agrado o el desagrado de la experiencia en cuestión. En el primer caso, lo que buscaremos será poseer aquello que nos resulta placentero; en el segundo, la respuesta natural será huir. Nuevamente, el pensamiento de Gabriel Marcel esclarece el sentido de lo que ya se ha dicho. La principal aportación del filósofo al respecto, es que el cuerpo que soy es el fundamento de cualquier experiencia de posesión. "mis posesiones, en cuanto me apego a ellas, se presentan como «complementos de mi cuerpo», de tal modo que «tener en el sentido» preciso la palabra, debe pensarse en analogía 
con la unidad sui generis que constituye mi cuerpo" (Kauffman, 2013: p. 75). El gran problema que se desprende de lo anterior, es que si bien es cierto que por un lado nuestro ser encarnado es la condición de posibilidad del acceso al mundo; también lo es que la encarnación condiciona nuestro acceso finito al mundo, a nuestro propio ser y al de Dios.

SJC señala, por usar la terminología escolástica, que nuestra percepción está mediada por la condición de ser que nos es propia: a cada ser corresponden por esencia determinadas operaciones. El contacto sensible con aquello que nos rodea y con nosotros mismos es el punto de partida tanto del conocimiento como de ese movimiento de la voluntad al que llamamos deseo, toda vez que en razón de nuestro ser encarnado comparecemos ante los demás en el mundo y somos capaces de abrirnos a la comparecencia de los otros y de las cosas.

Ahora bien, lo que a SJC verdaderamente le preocupa es si nuestra condición de seres encarnados -o como él dice, de almas encarceladas en la prisión del cuerpo- nos aporta alguna noticia sobre Dios o no. Como heredero de la tradición, el santo afirma que el ser invisible de Dios, "su eterno poder y deidad, se hacen claramente visibles desde la creación del mundo, siendo entendidas por medio de las cosas hechas, de modo que no tienen excusa" (Rom 1, 20). Sin embargo, al referirse a los males derivados de los apetitos -entendidos como movimientos desordenados de la sensualidad- deja en claro que aún para acceder a la noticia natural de Dios, es necesario ordenar la voluntad. Toda vez que, a través de los sentidos no solo nos enteramos de la presencia de las entidades que nos circundan sino que, simultáneamente, nos vemos afectados por ellas: deseamos poseerlas hasta el punto que el afán de conseguirlas, nos hace olvidarnos del fin sobrenatural para el cual fuimos creados.

La importancia del ascetismo es que, a través de las purgaciones activas el individuo consigue atenuar los efectos negativos de su ser encarnado. Esto es, se dispone favorablemente para el reconocimiento de la huella de la presencia de Dios en las criaturas. Por su parte, las purgaciones pasivas transforman su sensibilidad; ilustran su entendimiento con la luz tenebrosa de la sabiduría divina e inflaman su voluntad con el amor perfecto.

A partir de lo anterior, podría pensarse que para SJC el ser encarnado del hombre es más un obstáculo -una expresión del mal metafísico- que un medio para entrar en contacto con Dios. No obstante, hay que recordar que si Dios mismo asume la condición carnal del hombre es para redimirlo; para hacerla capaz de conocer y gozar a Dios, desde su limitación. Y que en Cristo, la carne ha sido redimida. 


\section{Conclusión}

A fin de descubrir si la vida tiene o no un sentido, y si vale la pena de ser vivida, resulta necesario hacer propias las preguntas de la antropología filosófica: indagar el origen de la existencia y tratar de descubrir las determinaciones esenciales de la condición de ser que nos es propia. Ya que de lo contrario, estamos condenados a vivir sin razón alguna, inmersos en el más profundo sinsentido.

El filosofar que se comprende a sí mismo como fenomenología, toma el punto de partida de su investigación de la experiencia: su propósito es hacer comprensible aquello que nos sale al paso, cotidianamente, para dotarlo de sentido. Por derivación, la tarea de la antropología fenomenológica es responder a la pregunta por el ser del hombre, a través de la descripción de las determinaciones esenciales que lo distinguen del resto de los entes. Para lo cual, lejos de atender a la manifestación de la humanidad de término medio -integrada por la enorme comunidad de quienes jamás se han preguntado qué es el hombre; dirige su mirada a aquellas manifestaciones de la humanidad en las que se encuentran realizadas todas aquellas posibilidades de la existencia que implican excelencia y plenitud. De entre las cuales destaca la figura del místico, toda vez que en él hay una clara consciencia del origen, las determinaciones esenciales y la finalidad última de la existencia.

A lo largo de esta meditación filosófica sobre la obra de SJC, se ha esclarecido poco a poco que el principal aporte del poeta místico al campo de la antropología no consiste en haber propuesto nuevas categorías de análisis para aclarar el ser del hombre; sino que su comprensión no surge de un conocimiento discursivo, sino de la experiencia directa de Dios.

En la primera sección de estas páginas se ha mostrado en qué sentido, con relación al hombre, el amor-ágape es el principio y la razón última de su existencia. Toda vez que Dios ha creado al hombre por amor y para amar, al tomar como modelo al Verbo. Más aún, si al crear al mundo y al hombre, al tomar como modelo al Hijo, Dios ya había dotado de dones a las criaturas, el perfeccionamiento de lo creado tiene lugar gracias a la encarnación. Ya que por obra de la encarnación, todo aquello que es asumido, es también exaltado.

De acuerdo con SJC, si Dios creó y redimió al hombre de sus pecados, fue para hacerlo convocarlo a la participación de la vida eterna, que consiste en amar a Dios como Él se ama a sí mismo en cada una de las Personas de la Trinidad, y ama al hombre. Lo que la redención nombra es el hecho de que la libertad para el bien y la salud solo pueden provenir de Dios porque son dones. 
Por naturaleza, somos imágenes de Dios. Gracias a ello estamos en condiciones de participar de su amor. Sin embargo, depende de nosotros la decisión de limpiarnos o no de todo aquello que empaña la belleza de nuestro ser, a fin de convertirnos en imagen y semejanza suya. La cual consiste en liberar espacio en nuestras vidas; es echar a un lado todo aquello que estorba nuestra comunicación y comunión con Dios; es relativizar y valorar en su justa dimensión la importancia que nuestros afanes cotidianos tienen, comparados con el fin último de la salvación, a fin de permitirle a Dios habitar en el castillo de nuestra alma.

La importancia del ascetismo es que, a través de las purgaciones activas el individuo consigue atenuar los efectos negativos de su ser encarnado. Esto es, se dispone favorablemente para el reconocimiento de la huella de la presencia de Dios en las criaturas. Por su parte, las purgaciones pasivas transforman su sensibilidad; ilustran su entendimiento con la luz tenebrosa de la sabiduría divina e inflaman su voluntad con el amor perfecto.

Podría pensarse que la purificación activa, a la que están aderezados los ejercicios y prácticas ascéticas, es una tarea exclusiva de los principiantes espirituales. Es cierto que la principal característica del principiante es la negación de los gustos, dependencias y apetitos que eclipsan la presencia interior de Dios. Sin embargo, ni siquiera en los estados más avanzados del camino espiritual se puede prescindir de la purificación.

Tras examinarse, cada uno podrá juzgar hasta qué punto la totalidad de sus actos cotidianos; de su manera de concebir la vida y de relacionarse con los demás, son reflejo de Dios. En todo caso, lo cierto es que mientras estemos vivos tenemos la posibilidad de limpiarnos; de liberarnos de nuestros vicios e inclinaciones erróneas, para acceder a la experiencia de Aquel que nos ha creado para hacernos partícipes de la vida eterna.

La enseñanza de SJC es que la única lejía capaz de devolverle al espejo de nuestra alma su pureza es la determinación de dejar atrás aquellos hábitos, gustos y contentos que lejos de acercarnos a Dios, opacan su presencia. Y que la gracia de Dios, que se da con la infusión del Espíritu Santo, es el agua cuya fuerza regeneradora libera nuestra voluntad de toda inclinación contraria al amor que Dios es.

\section{Referencias}

Bouyer, L. (2002). Diccionario de Teología. Barcelona: Herder.

Cabrera, I. (2006). Para comprender a la mística. En: Cabrera, I. \& Silva, C., (comps.). Umbrales de la Mística. México: UNAM. 
De la Cruz, San Juan (1994a). Cántico Espiritual B. En Obras Completas. Madrid: Biblioteca de Autores Cristiano, pp. 733-899. (1994b). Cartas. En Obras Completas. Madrid: Biblioteca de Autores Cristianos, pp. 200-235. (1994c). Subida del Monte Carmelo. En Obras Completas. Madrid: Biblioteca de Autores Cristianos, pp. 241-482.

De Jesús, T. (1972). Moradas del castillo interior. Barcelona: Editorial Brugera.

Graef, H. (1970). Historia de la mística. Barcelona: Biblioteca Herder.

Kaufmann, S. (2013). La metafísica de la existencia humana de Gabriel Marcel. En: Véritas, [marzo 28], pp. 65-84.

Pérez, A. (2002). El mundo como creación. Ensayo de filosofía teológica. Madrid: Ediciones Encuentro.

Ratzinger, J. (2007). Jesús de Nazaret. Madrid: La esfera de los libros.

Sesboëé, B. (1997). Redención y salvación en Jesucristo. En: González de Cardenal, O.; González Faus, J. I. \& Ratzinger, J. (Eds.). Salvador del mundo. Historia y actualidad de Jesucristo. En: Cristología fundamental [pp. 113-132]. Salamanca: Secretariado trinitario. 